\title{
Experimental investigation of an Air Source Heat Pump
}

\author{
Mugurel Florin Tălpigă ${ }^{1, *}$, Florin Iordache ${ }^{1}$, and Eugen Mandric ${ }^{1}$ \\ ${ }^{1}$ Faculty of Building Services, Technical University of Civil Engineering of Bucharest, Bucharest, Romania
}

\begin{abstract}
An experimental investigation were driven to catch all working parameters of an Air Source Heat Pump such as temperature differences between refrigerant working states and evaporator respectively condenser environment temperatures. Heat Pump compressor were monitored to know inlet and outlet refrigerant temperatures to build working diagram of the heat pump in heating configuration. At condenser, a plate heat exchanger is used to discharge the energy from refrigerant to water, liquid used in secondary circuit. Heat exchanger temperatures of refrigerant and water were monitored to drive the working diagram of the heat exchanger equipment. Current consumption of Heat Pump were registered together with heat exchanger secondary circuit temperature differences and his water flow to estimate Seasonal Performance Factor during experiment.
\end{abstract}

\section{Introduction}

Energy has led during time all earth environment evolutions, wildest beings and in the lasts millenniums human beings with their intelligence and conscience. After primary needs like food and living space, first in come was comfort in urban housing, transportation, or social integration. Preamble of urbanisation is living environment comfort, such thermal demand in winter or in summer, complex sum of all building services and today communication speed as part of future development.

Through a human specific activity, the high level education and research domain today embrace an empirical success, due to increasingly interest to earth climate saving techniques, revolutionary building materials, energy saver technologies and efficiency strategies in heat-up or cool down of internal building environment. A path to decrease the primary energy demand is to use renewable energy as air, water or ground accumulated heat over the past years, respectively solar energy transmitted to earth by solar irradiation.

In research area a good tool for designing is simulation software. Today researchers, engineering, technicians have computational environment to simulate a system, a theoretical method to write equipment mathematical low, or simulate the building facilities management algorithm to find an appropriate value for the minima/maxima of system description function as optimal account. Additionally to simulation, experiment will confirm or give us a new value of searched parameter to calibrate the real equipment comparing computational algorithm result.

Mathematical modelling of thermal system will always be a challenging engagement, diversity of systems and mixing technologies being a real thread in majority of equipment. Hybrid systems are most frequent subjected to high complexity. Global energy consumption is increasing yearly and climate change being a consequence [1-4].

\section{Mathematical model}

Carnot cycle was historically used as physical model for work to heat and reverse conversion cycle [5] for heat pumps thermal evaluation. Is the starting point. Just writing the right cycle between upper and lower Carnot cycle temperatures, make the difference. Describing the realistic Carnot cycle is a matter of knowing heat pump working principle, the refrigerant cycle used for specific application [6], conduct to confident analyse data after simulation with good result after implementation. Taking into consideration the compressor isentropic efficiency and electrical power consumption, we can write Equation (1) and for Coefficient of Performance it is commonly used Equation (2) [7]:

$$
\begin{aligned}
& P_{C D}=P_{V P}+\eta_{C} \cdot P_{E L} \\
& C O P_{C D}=P_{C D} / P_{E L}
\end{aligned}
$$

The transfer of heat from condenser and to evaporator, to the environment of condenser respectively from the environment of evaporator, is realized by the heat pump which should work in different temperatures compared with those environments. The heat pump condenser temperature should be higher than his environment and also the temperature of evaporator of the heat pump is always below the temperature were evaporator is immersed or exposed [8-9].

$$
\begin{gathered}
C O P_{C D}=\eta_{C} \cdot\left(\theta_{C D}+\Delta_{C D}+273.15\right) /\left(\theta_{C D}-\theta_{V P}+\Delta_{C D}+\Delta_{V P}\right) \\
P_{C D}=\eta_{C} \cdot P_{E L} \cdot\left(\theta_{C D}+\Delta_{C D}+273.15\right) /\left(\theta_{C D}-\theta_{V P}+\Delta_{C D}+\Delta_{V P}\right)
\end{gathered}
$$

\footnotetext{
* Corresponding author: talpiga.mugurel@gmail.com
} 
The evaluation of COP is done from the condenser point of view, considering that for heating this performance is a term of interest. As a rapport between condenser and compressor electrical power consumption, and with Equation (3), we can easily describe the correlation between electrical power consumption, compressor efficiency and heat pump refrigerant cycle specification resulting Equation (4).

For a heat pump which produce hot water at condenser we can draw a physical schematic diagram in Figure 1, to be able to write the thermal balance which handle the equipment from a mathematical point of view. Diagram present only the compressor, the condenser, schematically and theoretically as a heat exchanger, were the refrigerant condensate and the heat transported by the fluid which is carried into the heating unit by flow pump.

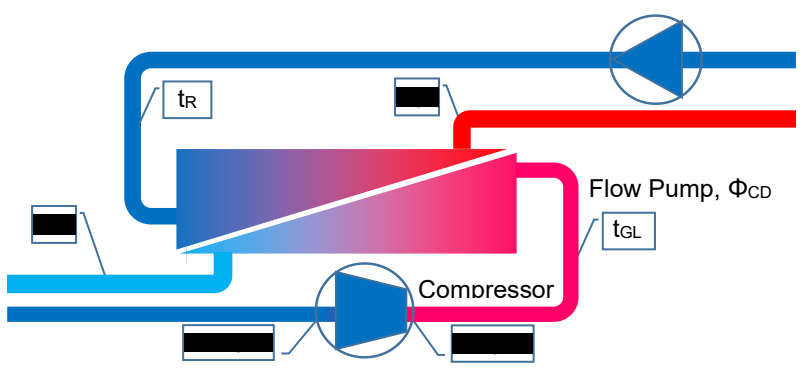

Fig. 1. Heat pump condenser physical model.

For a given consumer, the power at condenser outlet should be well dimensioned to satisfy the heating/cooling needs for specific period of time but also, together with accumulation system to face all possible edge worst weather conditions always present and unpredictable in cold or hot seasons. Condenser power, when inlet and outlet temperatures from secondary unit of heat exchanger are available, together with fluid mass/volume flow, can be easily written as a product of temperature difference, flow, and fluid characteristics, described by Equation (5).

$$
P_{C D}=0.016 \cdot Q_{C D} \cdot \rho_{W^{*}} c_{W} \cdot\left(t_{C}-t_{R}\right) \cdot 10^{-3}
$$

For known data, such as temperatures of refrigerant state, condensing/evaporating temperatures, we can simulate the behaviour of system, we can extract whatever parameters are in interest but also to define some parameters which cannot be measured. By equalization, Equation (4) and Equation (5) become together the expression of thermal balance between evaporator and condenser environment, given by Equation (6), were parameters cth and ctl are described by Equation (7) and Equation (8), noted RCTCs (refrigerant cycle temperatures coefficients), we are able to estimate electrical power, on compressor inlet. This is possible taking into consideration compressor type efficiency, known RCTCs, but, more important condenser power.

$$
\begin{gathered}
P_{E L}=\eta_{C}^{-1} \cdot\left(c_{t h}-c_{t l}\right) \\
c_{t l}=\left(\theta_{V P}-\Delta_{V P}\right) /\left(\theta_{C D}+\Delta_{C D}+273.15\right)
\end{gathered}
$$

$$
c_{t h}=\left(\theta_{C D}+\Delta_{C D}\right) /\left(\theta_{C D}+\Delta_{C D}+273.15\right)
$$

This is a direct approach of electrical power based on some system characteristics such as compressor construction type and refrigerant properties. High and low temperature coefficients give through a mathematical expression, how much influence have temperature differences in electrical power consumption, correlated with condenser power. That's as minimum as possible is temperature differences between condensing and evaporator states, therefore power consumption decrease for same condenser power. Also, as much as possible compressor efficiency is bigger the electrical demand will decrease. Those heat pump properties are generally known and this paper approach comes with a specific form to provide an equation which stand to mathematical model for heat pump to be used in numerical simulation.

Evaporator power is generally written by difference from condenser power and a part of electrical power through compressor efficiency. This is revealed by Equation (9) generally valid for a constant evaporator temperature.

$$
P_{V P}=P_{C D}-\eta_{C} \cdot P_{E L}
$$

Due to evaporator overheating behaviour and pressure losses with refrigerant transportation into pipes refrigerant vapours are overheated and evaporator power described by Equation (9) is decreased. Real temperature of liquid and vapour inside equipment is different than ideal condition. Compressor maintain the pressure inside evaporator equipment but cause of overheating the temperature is higher comparing with corresponding temperature at refrigerant pressure state. Rapport between real evaporator power and ideal condition evaporating power described by Equation (9) is noted as evaporator state efficiency, and defined by Equation (10).

$$
\eta_{V P}=P_{V P_{-} R E A L} / P_{V P}
$$

By equalization Equation (9) and Equation (10), become the expression of real evaporator power, with losses and overheating effect taken into consideration. Equation (11) reveal the real behaviour of evaporator equipment, when by designing the parameters states, the overheating and pressure losses are a real constrain which merge to a evaporator power lower than ideal equipment. Vapour boiling inside equipment inevitably will be overheated by equipment wall which are at a temperature above the liquid temperature.

$$
P_{V P-R E A L}=\eta_{V P} \cdot\left(P_{C D}-\eta_{C} \cdot P_{E L}\right)
$$

Parameters identification, is an important step in experiment design. Knowing what are the needs to create an experimental study and necessity of identification of certain parameters, is an important objective. Priory to experimental plan, a SW based simulation is necessary to established what is known in equipment functionality, what can be measured 
directly on the experiment bench and what data cannot be measured directly and required a mathematical calculation.

Some of this paper suppositions are related evaporator efficiency comparing ideal condition, isentropic compressor efficiency, comparing ideal compressor without losses. Refrigerant states parameters, such evaporating and condensing pressure corresponding temperatures, differences between environment and refrigerant temperatures are parameters which can be measured directly on bench. Electrical power consumption can be measured directly using a data acquisition station for currents and voltages. For compressor efficiency Equation (6) is re-drawn into Equation (12).

$\eta_{c}=\left[P \cdot\left(\theta_{C D}+\Delta_{C D}+273.15\right) /\left(\theta_{C D}-\theta_{V P}+\Delta_{C D}+\Delta_{V P}\right)\right]^{-1} \cdot P_{C D}$

For a specific equipment, condensing temperature can be directly measured with temperature resistor or thermocouple sensors, or condensing pressure can be measured by refrigerant corresponding manifold.

For evaporator state, method is the same as for condenser. The differences is in select the right manifold indicator in case cold or hot equipment is evaluated. The condensing and evaporator temperatures can be stored in specific data tables or can be measured by manifold and manually the pressures and temperatures being noted in the table.

Condenser power is evaluated by thermal balance at condenser equipment. For Equation (12) a heat exchanger were imagined, thermal balance being wrote as an equation between flow rate inside secondary of heat exchanger and temperature of water at inlet and exist pipes of it. The liquid have a specific heat and a specific density noted $c_{\mathrm{w}}$ respectively $\rho_{\mathrm{w}}$ in Equation (5) and $Q_{\mathrm{cd}}$ as flow rate in $1 \cdot \mathrm{min}-1$. Constant 0.016 represent te correlation between minutes (from flow rate) and seconds from Joule to Watt conversion. All measured parameters together, will return after mathematical calculation the value of isentropic efficiency of compressor.

\section{Measured data list}

Measured data, as previously analysed for compressor efficiency identification are given by Equation (12). Electrical power can be registered using a data acquisition station, a power meter or energy registration unit. Electrical power for three phase AC current, is a product between current, voltage and power factor, and is given by Equation (13).

$$
\begin{gathered}
P_{E L \_s y m}=3^{0.5} \cdot U \cdot I \cdot \cos (\Phi) \cdot 10^{-3} \\
P_{E L_{-} \text {sym }}=\cos (\Phi) \cdot 10^{-3} \cdot \Sigma\left(U_{i} \cdot I_{i}\right)
\end{gathered}
$$

Electrical energy comprise entire electrical power consumption during a period of time. Because heat pumps didn't work continuously and his power can be different from time to time, due to inverter technology and refrigerant states, total energy can be written as a sum of all energy measurements in constant periods of time, specially set for constant values of current and voltage.

$$
E_{\text {sym }}=1.73 \cdot \cos (\Phi) \cdot 10^{-3} \cdot \Sigma\left(U_{i} \cdot I_{i} \cdot \tau_{i}\right)
$$

The Equation (15) is true when three phase symmetrical load is applied on power consumption. This represent an equal current value on each phase.

Power factor is an electrical compressor parameter and depend on each technology of compressors. For this paper, the power factor parameter value, is selected from equipment datasheet provided by manufacturer. This parameter is used for correction of apparent power, given by product between current and voltage measurements. Due to reactive power of inductive like compressor coils, real power is smaller compering direct measurements. Generally this correction can be made by data acquisition station, through an initial setup of power facto value, or can be introduced after measurements, when a dedicated energy calculation is done. Sampling rate should be equal to all three phases, and can be also a constant sampling rate, depends on data acquisition tool.

Table 1. Main parameters list.

\begin{tabular}{|l|l|l|}
\hline \multicolumn{2}{|c|}{ Main parameters } & units \\
\hline param & description & $\mathrm{A}$ \\
\hline $\mathrm{I}_{1}$ & current phase 1 & $\mathrm{A}$ \\
\hline $\mathrm{I}_{2}$ & current phase 2 & $\mathrm{A}$ \\
\hline $\mathrm{I}_{3}$ & current phase 3 & ${ }^{\circ} \mathrm{C}$ \\
\hline $\mathrm{t}_{\mathrm{CD}}$ & condensing temperature & ${ }^{\circ} \mathrm{C}$ \\
\hline $\mathrm{t}_{\mathrm{VP}}$ & evaporator temperature & ${ }^{\circ} \mathrm{C}$ \\
\hline $\mathrm{t}_{\mathrm{C}}$ & heat exchanger secondary out temperature & ${ }^{\circ} \mathrm{C}$ \\
\hline $\mathrm{t}_{\mathrm{R}}$ & heat exchanger secondary input temperature & $\mathrm{I}$ min \\
\hline $\mathrm{Q}_{\mathrm{CD}}$ & heat exchanger secondary liquid flow rate & $\mathrm{V}$ \\
\hline $\mathrm{U}_{1}$ & voltage phase 1 & $\mathrm{V}$ \\
\hline $\mathrm{U}_{2}$ & voltage phase 2 & $\mathrm{V}$ \\
\hline $\mathrm{U}_{3}$ & voltage phase 3 & bar \\
\hline $\mathrm{P}_{\mathrm{VP}}$ & evaporator pressure & bar \\
\hline $\mathrm{p}_{\mathrm{CD}}$ & condensing pressure & hour \\
\hline$\tau$ & sampling rate & \\
\hline & & \\
\hline
\end{tabular}

In Table 1 is presented the list of parameters to be measured and registered during experimental data registration. Are proposed two types of measurements; main parameters being used in mathematical modelling calibration presented in above methodology, respectively some secondary measurements parameter list, being helpful for additional evaluations of equipment.

Generally, temperature measurements are subjected to an evaluation of acquisition sensor calibration. Over time, resistive sensors and thermocouples register degradation from their initial values, when return data were calibrated. A representative measurement should take into account a new calibration, or used the last calibration in warrant period of time. Registered curves of sensors types are directly dependent with measured temperature value, sometimes the difference between positive and negative temperatures or big temperature intervals not being a constant value. 


\section{Experimental study plan}

Experimental study, main purpose of this paper, to be used in model calibration, require a deeper analyze of studied equipment, measurements acquisition stations and calibration necessities for used sensors.

Starting from model description, the experimental study were performed on an ASHP for building heating purpose and DHW production. Model description of this study targets the isentropic efficiency and evaporator respectively condenser temperature differences comparing their environments of a heat pump. Those values are used after in the mathematical model for energy evaluation of such systems, in a specific period of time and for a specific customer.

The equipment is a Mitsubishi Electric ZUBADAN PUHZ-SHW112YHA R410A refrigerant based ASHP system. A three phase compressor power related electrical consumption is around $2.5 \mathrm{~kW}$, and come with two fan speed for forced air convection purpose, with electrical consumption equal $0.074 \mathrm{~kW}$.

External unit presented in Figure 2 contain the most critical elements of the heat pump. In case of heating necessity evaporator, compressor, expansion valve and reversing unit are comprise by the unit. Also, automation oh heat pump and inverter for driving the compressor are included. Evaporator in case of heating purpose or condenser in case of cooling needs, is built from refrigerant cooper coils with thin aluminum plates register for heat transfer.

Terminal plugs for refrigerant gas (point 1 in the picture) and liquid (point 2 in the picture) lines, are available to be handled from exterior, for maintenance or installation purpose. Also a removable service panel make possible electrical connections for power supply and also internal unit cable connections. The two fans useful for air source equipment increased heat transfer efficiency, are electrically operated by the same inverter unit, being able to permanently sweep their rotating speed.

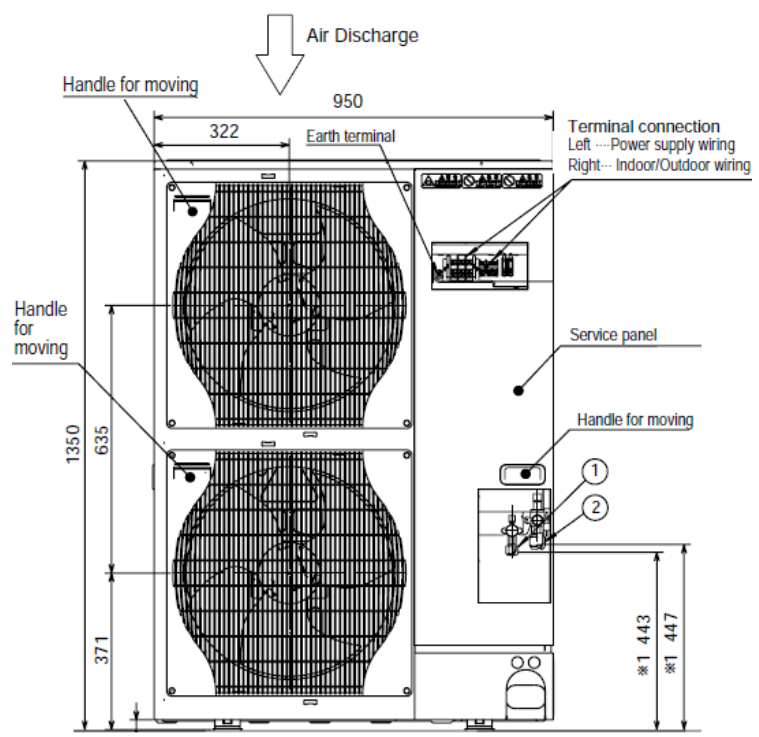

Fig. 2. Experimental heat pump external unit.
Heat pump external unit have implemented a high efficient heat pump technology, with 8 thermistors for temperature measurements, mounted in key positions like liquid and discharge line, or evaporator and suction lines. Three linear expansion valves are included, two as primary and secondary refrigerant expansion valves, for liquid expansion into power receiver respectively into evaporator(in heating) or condenser(in cooling); the third expansion valve is used in parallel connection for heat interchange circuit when used.

Internal unit is comprise of a heat plate exchanger, a circulating pump for secondary liquid flow, the water temperature controller, DHW accumulator and heating water accumulator. Heating accumulator is a 200 liters insulated water tank, with two entries for hot water and return water of heating equipment respectively two outputs, one for cooled water which entry inside plate heat exchanger and the last one going to heating equipment of the building.

Building heating equipment is formed by two low temperature floor units, with their specific automation and agent preparation units. A main circuit for floor heating units is present. Water alimentation circuit is possible due to an additional circulating pump, able to drive the water through the system at the required flow rate. Circulating pump for secondary unit of heat exchanger, is an WILO Yonos PICO 25/1-6-(EU3), with maximum power consumption equal to $40 \mathrm{~W}$ able to deliver a flow rate above value of $151 \cdot \mathrm{min}-1$.

Selection between DHW and heating water tanks is made with a three way hydraulic valve, in priority being DHW tank instead of heating unit which is considered having a sufficient thermal inertia until hot water demand is delivered at required temperature value. DHW water tank have an immersed coil for heating agent, specific clean water being delivered through comparing with daily heated water which have a based ground water source. Water tank for DHW and three way valve connection are presented inside Figure 3.

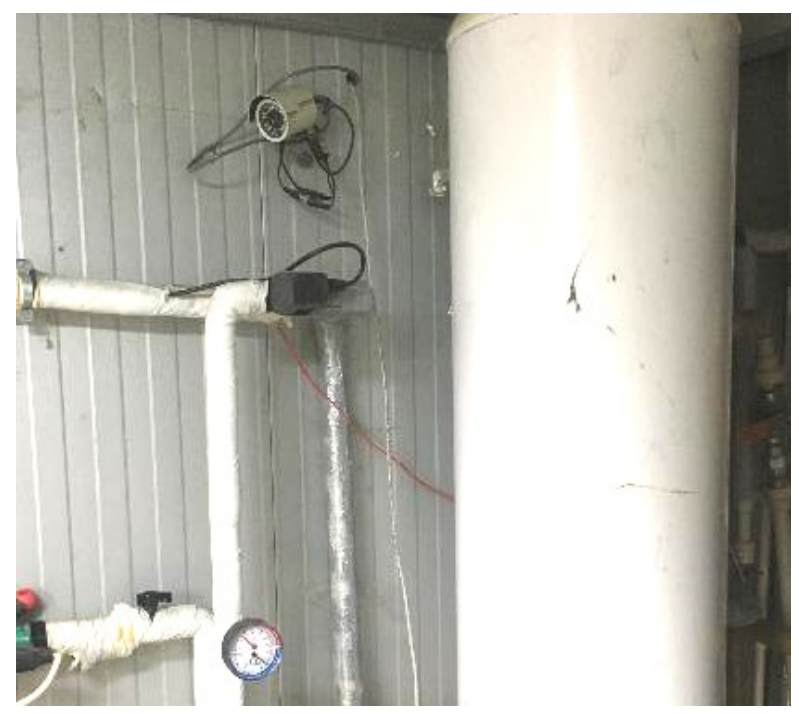

Fig. 3. Experimental study bench DHW water tank and 3 way selection valve. 
For heating accumulation tank, the installed system is based on 200litres tank equipped with an expansion tank to keep the required pressure into the system. For heating and DHW preparation, the system condenser consist of a heat plate exchanger with $500 \mathrm{~mm}$ height and $120 \mathrm{~mm}$ depth, built from cooper foils with 2 plugs for each primary respectively secondary circuit. Secondary circuit plugs are standard 3/4inch connection and primary plugs specially designed for hard soldering, where condensate liquid respectively hot vapours lines are connected.

For phase currents measurements a PicoLog CM3 acquisition data logger from Pico technology is used. Current clamp accuracy $+/-2 \%$ with a 0.1 to 200 Amperes AC RMS range with a scaling factor equal to $1 \mathrm{mV} / \mathrm{A}$. Data logger accuracy is $+/-1 \%$ for measurements under $20 \mathrm{mV}$ and $+/-2.5$ for currents up to $200 \mathrm{mV}$. For this paper, the accuracy of interest regarding CM3 voltage, is kept $+/-1 \%$ due to currant range which not pass $15 \mathrm{~A}$. Temperatures and flowmeter are sampled and registered with Ahlborn Almemo 5690-2 data acquisition station and saved into PC through a USB connection. Data logger in working progress is presented in Figure 4. System consist in dedicated measurements plugs connections, for each type of sensors connectors having internally built in analog voltage scaling devices. This system is high performance and high resolution with increased speed of sampling, being able to register over 50 data per second. Data input plug modules are automatically detected and measurements conversion are directly displayed into their specific units. The format of information is text based and saved through Ahlborn SW delivered by same manufacturer. Evaporator temperature sensor return a dry bulb value and all the other temperatures are type $\mathrm{K}$ thermocouple sensors exposed into. Calibration were conducted to see the differences related to a reference sensor and measurements accuracy. Calibration station were done inside laboratories of Technical University of Civil Engineering - Faculty of Building Services and presented in Figure 6. Calibration station for reference sensor is LAUDA DigiCal DGS 2 and together with LAUDA calibration bath with standard distilled water liquid used to immerge the sensors. Data were manually registered into a text document and future used for calibration results values calculation

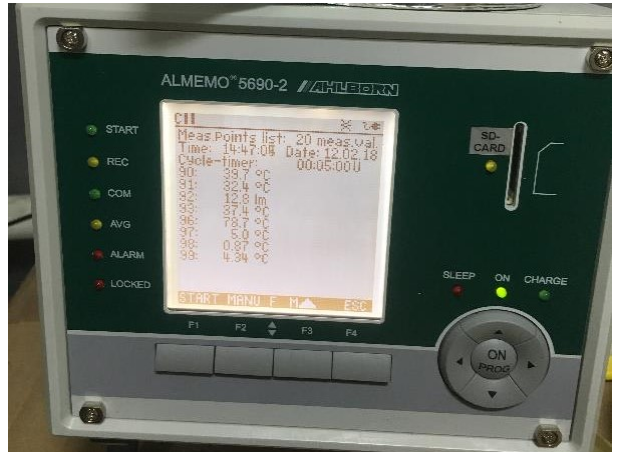

Fig. 4. Almemo 5690-2 system in working process.

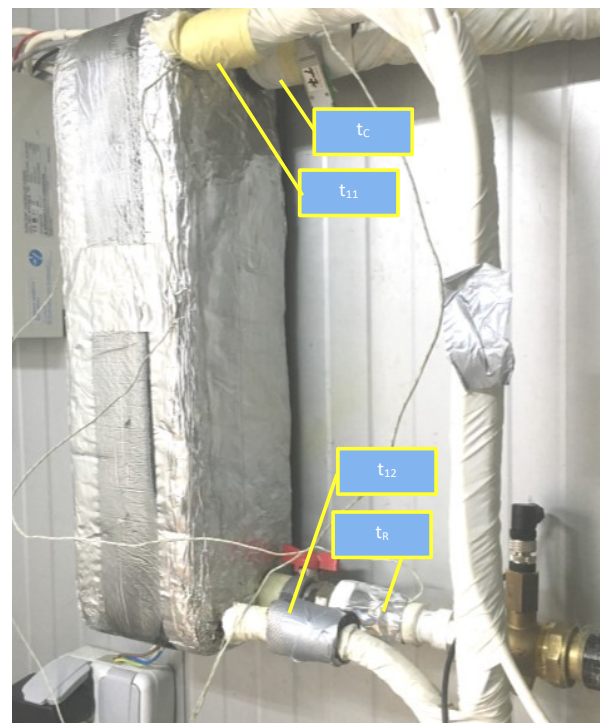

Fig. 5. Heat exchanger measurement points.

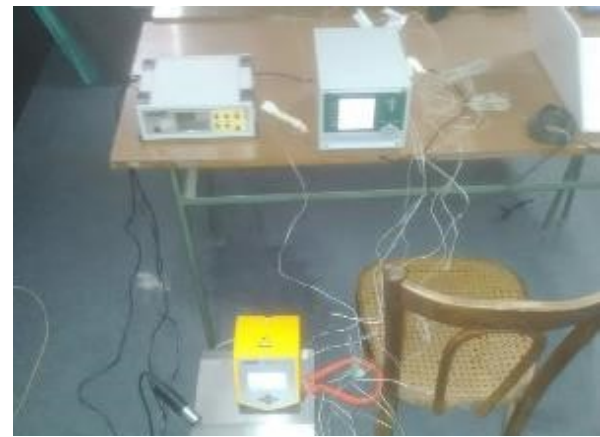

Fig. 6. Thermocouples calibration bench.

Inside Table 2 multiple temperatures are presented. Calibration reference sensor are listed in the left of the table with red color cell fill type, representing the displayed value of LAUDA DigiCal thermometer at the set value of LAUDA bath listed in the first column cells of table. Light orange values in a column were used to calculate the average level and displayed in dark orange inside average row. As can be seen, the selected values for averaging are selected only to satisfy the range of temperatures were thermocouples work in experimental study. As an example, for input temperature of gas at suction line of compressor, temperature values didn't overpassed $20^{\circ} \mathrm{C}$ comparing output compressor temperatures values in working process which didn't fall below values of $40^{\circ} \mathrm{C}$..

Related sensor measurements can be observed in circle points and average values plotted in bars with values displayed on below end point correlated in secondary axe.

Interesting values are displayed on graph. Measurement thermocouples present closer calibration results with one exception related with return water temperature from heating accumulation tank. This high deviation, comparing with the other thermocouples results, is caused by thermocouple possible defects like contact resistance between the two metals and changed over time due to ageing effect. Calibration results 
obtained by this measurement are used in data processing chapter for parameters identification.

Table 2. Experimental study bench thermocouples measurements calibration results and reference sensor values for 6 temperatures

\begin{tabular}{|c|c|c|c|c|c|c|c|c|c|}
\hline $\begin{array}{c}\text { set } \\
\text { value }\left[{ }^{\circ} \mathrm{C}\right]\end{array}$ & $\begin{array}{c}\text { Ref } \\
\text { sensor }\end{array}$ & & time & $t_{c}$ & $t_{R}$ & $t_{12}$ & $\mathrm{t}_{11}$ & $\mathrm{t}_{\text {out_c }}$ & $t_{i_{n} \_}$ \\
\hline \multirow{2}{*}{$1{ }^{\circ} \mathrm{C}$} & \multirow{2}{*}{0,91} & \multirow{2}{*}{${ }^{\circ} \mathrm{C}$} & 11:33:54 & 1,7 & 3,4 & 1,7 & 1,7 & 1,8 & 1,6 \\
\hline & & & calibration value & $-0,79$ & $-2,49$ & $-0,79$ & $-0,79$ & $-0,89$ & $-0,69$ \\
\hline \multirow{2}{*}{$10^{\circ} \mathrm{C}$} & \multirow{2}{*}{10,26} & 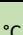 & 11:41:06 & 10,5 & 11,1 & 10,6 & 10,5 & 10,6 & 10,4 \\
\hline & & $C$ & calibration value & $-0,24$ & $-0,84$ & $-0,34$ & $-0,24$ & $-0,34$ & $-0,14$ \\
\hline \multirow{2}{*}{$20^{\circ} \mathrm{C}$} & \multirow{2}{*}{20,19} & ${ }^{\circ}$ & $11: 50: 39$ & 20,5 & 19,2 & 20,5 & 20,5 & 20,5 & 20,5 \\
\hline & & $c$ & calibration value & $-0,31$ & 0,99 & $-0,31$ & $-0,31$ & $-0,31$ & $-0,31$ \\
\hline \multirow{2}{*}{$30^{\circ} \mathrm{C}$} & \multirow{2}{*}{30,02} & o & $11: 59: 05$ & 30,5 & 27,1 & 30,4 & 30,5 & 30,5 & 30,4 \\
\hline & & $\mathrm{C}$ & calibration value & $-0,48$ & 2,92 & $-0,38$ & $-0,48$ & $-0,48$ & $-0,38$ \\
\hline \multirow{2}{*}{$40^{\circ} \mathrm{C}$} & \multirow{2}{*}{39,97} & & 12:05:39 & 40,5 & 36,1 & 40,3 & 40,4 & 40,4 & 40,4 \\
\hline & & 0 & calibration value & $-0,53$ & 3,87 & $-0,33$ & $-0,43$ & $-0,43$ & $-0,43$ \\
\hline \multirow{2}{*}{$50^{\circ} \mathrm{C}$} & \multirow{2}{*}{49,85} & & $12: 12: 55$ & 50,6 & 46,3 & 50,4 & 50,5 & 50,6 & 50,5 \\
\hline & & $c$ & calibration value & $-0,75$ & 3,55 & $-0,55$ & $-0,65$ & $-0,75$ & $-0,65$ \\
\hline \multicolumn{4}{|c|}{ Average } & $-0,52$ & 2,8 & $-0,39$ & $-0,52$ & $-0,59$ & $-0,38$ \\
\hline \multirow{4}{*}{\multicolumn{4}{|c|}{ legend }} & & \multicolumn{5}{|c|}{ values used for mediation } \\
\hline & & & & & \multicolumn{5}{|c|}{ average calibration value } \\
\hline & & & & & \multicolumn{5}{|c|}{ table fill } \\
\hline & & & & & \multicolumn{5}{|c|}{ calibration value } \\
\hline
\end{tabular}

Experimental study bench is installed into a production factory in Ciocanesti town Dambovita County. Placement location of heat pump evaporator is at the North of the building, with all day working in a shady environment, solar irradiation never touching the external unit. Experimental measurements were conducted in a cold period of winter during $21-24$ February 2018.

Condensing and evaporation temperatures used in mathematical model description were manually read on a specific R410a refrigerant manifold. Cold and hot gas lines plugs are R410a standards refrigerant connectors with red color for high pressure line respectively blue color for low pressure line. Measurements shows the values of 7,8Bar corresponding with $2^{\circ} \mathrm{C}$ evaporating respectively 35 bar corresponding $57^{\circ} \mathrm{C}$ condensing temperatures. Temperature differences were evaluated with Equation (16) and Equation (17) were logarithmic medium temperature is given by Equation (18). At the condenser, the condensing temperature is considered as being a value of temperature inside interval of condensing secondary circuit temperature difference, by evaluation with logarithmic medium technique.

$$
\begin{gathered}
\Delta_{\mathrm{VP}}=\mathrm{t}_{\mathrm{ext}}-\mathrm{t}_{\mathrm{VP} \_ \text {man }} \\
\Delta_{\mathrm{CD}}=\mathrm{t}_{\mathrm{ml} \_ \text {cond }}-\mathrm{t}_{\mathrm{CD} \_ \text {man }} \\
\mathrm{t}_{\mathrm{ml} \_ \text {cond }}=\left(\mathrm{t}_{12}-\mathrm{t}_{11}\right) / \ln \left(\mathrm{t}_{12} / \mathrm{t}_{11}\right)
\end{gathered}
$$

Temperatures differences measurements with manifold show for constant evaporator environment temperature the compressor driver is able to maintain a constant pressure inside evaporator for a good control of evaporator heat transfer rate. The pressure in condenser correspond to a condensing temperature setup which were varied during measurement between $35^{\circ} \mathrm{C}$ and $45^{\circ} \mathrm{C}$ with a $5 \mathrm{~K}$ temperature steps. For those 3 condenser temperature setup, the heat pump only change the condensing temperature varying compressor working frequency or change the pressure stop threshold.

\section{Registered data processing and parameters identification}

Registered data, is a result of the experimental study during 4 days from 21.02.2018 until 24.02.2018, time interval were more than 25000 samples for each of 13 measurement parameters.

For evaporator environment temperatures, input and output, temperatures registered shows a sampling error for external temperature or inlet air temperature measured with a dry bulb temperature sensor. This error is a consequence not investigated but the inlet air temperature is obtained by calculation with medium temperature differences, obtained at the second experiment.

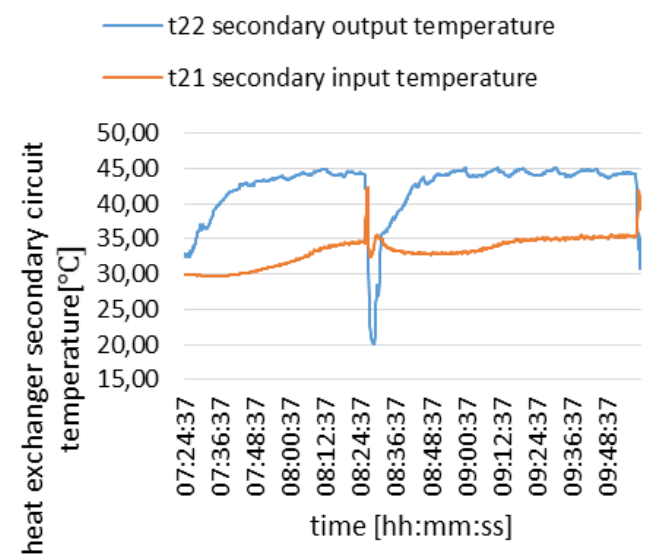

Fig. 7. Experimental study bench measurements of condenser secondary circuit temperatures from 21.02.2018.

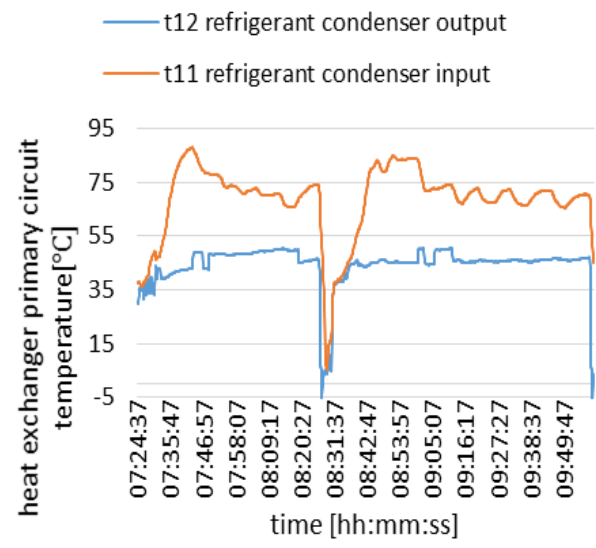

Fig. 8. Experimental study bench measurements of condenser primary circuit temperatures from 21.02.2018.

Average value of temperature drop, graphically shown on Fig of air inside evaporator have value of $1.19 \mathrm{~K}$. The average value obtained were used to establish the right external temperature of the 
environment from which heat is extracted by refrigerant.

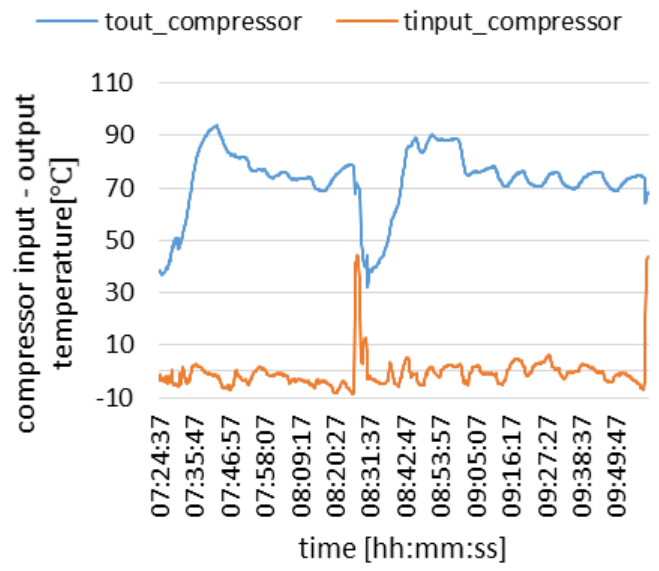

Fig. 9. Experimental study bench measurements of input and output compressor plugs temperatures from 21.02.2018.

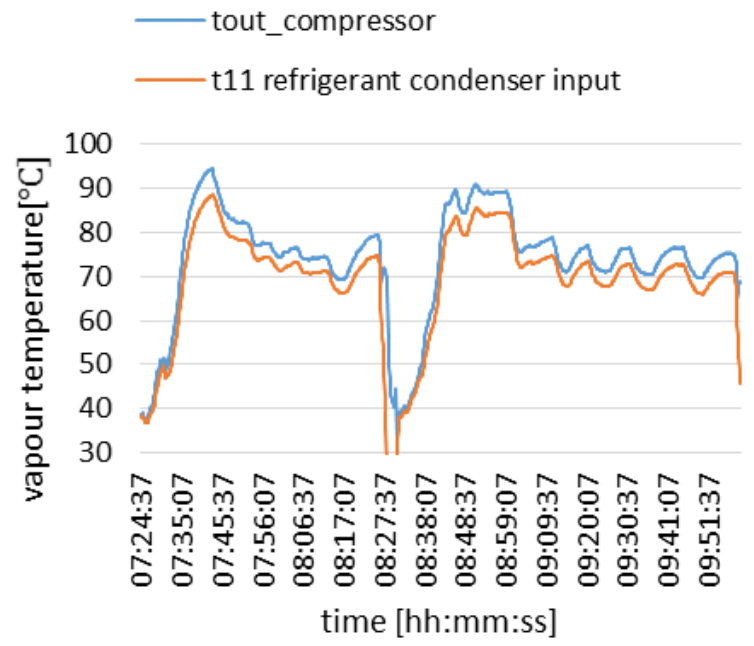

Fig. 10. Experimental study bench measurements vapor temperature drop between compressor output and condenser input from 21.02.2018.

The evaluation of compressor efficiency is now easy to be done, sing condenser temperature as a logarithmic medium value between inlet and outlet of condenser heat exchanger. For evaporator is used the evaporator outlet air temperature with difference drop added to it value. For its value, efficiency is evaluated with Equation (19) using Equation (5) for condenser power and PEL_sym for electrical power.

Condensing temperature is obtained using inlet and output plugs temperatures of secondary heat exchanger circuit and temperature difference at condenser and evaporator being before established. Both parameters used in this paper have $20.17 \mathrm{~K}$ for condensing and respectively $7.80 \mathrm{~K}$ for evaporator. Rewriting we obtain an equation were only condenser and evaporator temperatures together with condenser and electrical power are used.
Electrical power is obtained after summing of power on all three lines, using a power factor coefficient equal 0.9 .

In 15 are presented model evaporator and condensing temperatures. Those temperature represent real condensing and evaporator temperatures for which are added or subtraction temperatures difference for condenser respectively evaporator.

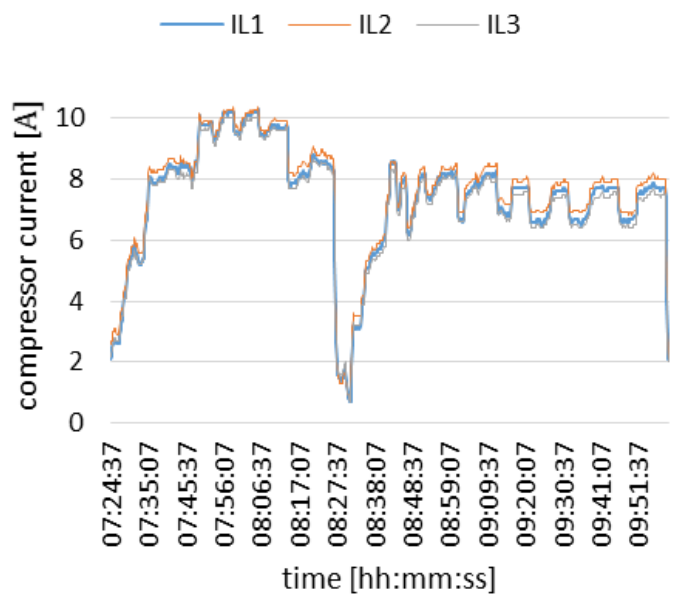

Fig. 11. Experimental study bench measurements of compressor input current from 21.02.2018.

$$
\begin{gathered}
\eta_{C}=\left(t_{m l_{-} \text {cond }}+\Delta_{C D}+273.15\right) /\left(t_{m l_{-} c_{c o n d}-}\right. \\
\left.-\theta_{V P}+\Delta_{C D}+\theta_{V P}\right)^{-1} \cdot\left(P_{C D} / P_{E L}\right) \\
-\mathrm{t} \text { exterior } \quad \mathrm{t} \text { out evaporator }
\end{gathered}
$$

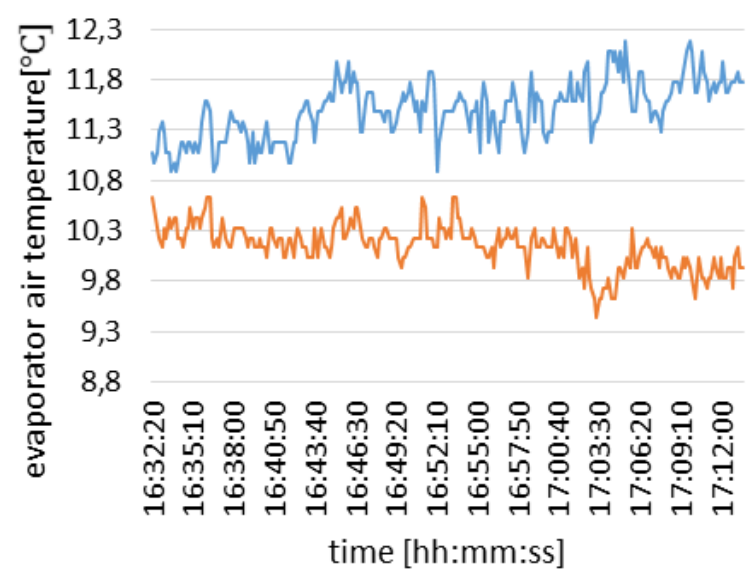

Fig. 12. Experimental study bench measurements of temperature drop in evaporator input and output 28.03.2018.

$\eta_{C}=\left(t_{m l} l_{c o n d}+293.15\right) /\left(t_{m l} l_{c o n d}-\theta_{V P}+27.97\right)^{-1} \cdot\left(P_{C D} / P_{E L}\right)$

A mean value of 0.5038 were obtained for compressor efficiency in this time interval. Registration and calculation show that compressor efficiency is also a dynamic parameter which is depending of system calibration or temperature setup. 
This value will be kept in next chapter for program calibration.

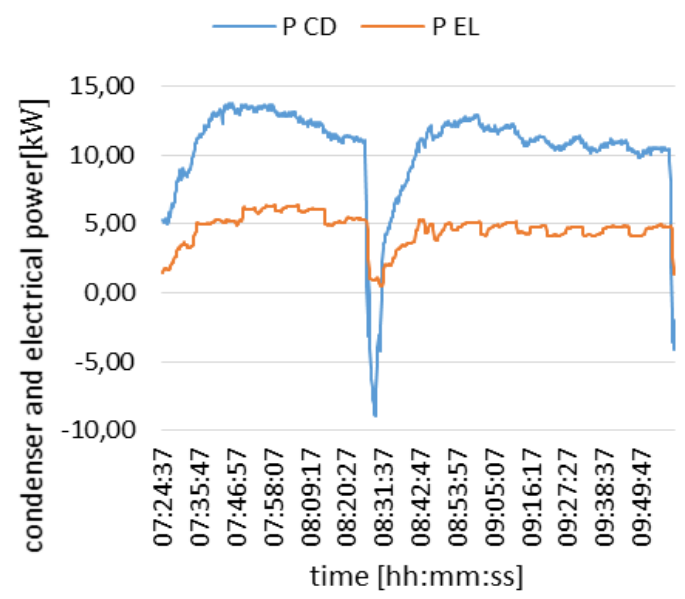

Fig. 13. Condensing power and electrical power consumption for the experiment of 21.02.2018.

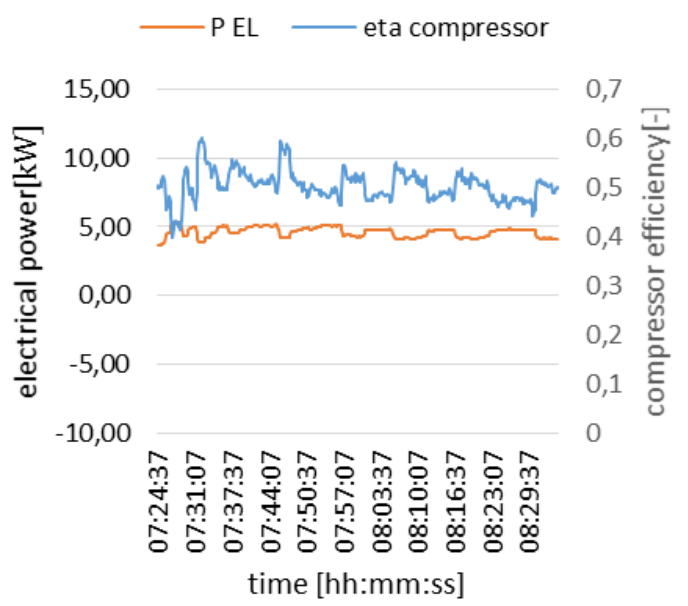

Fig. 14. Electrical power efficiency and efficiency mean value for 07:20 to 08:35 data of 21.02.2018.

\section{Results and discussion}

Simulation program calibration is conducted to setup the simulation program for evaluation of equivalence between the mathematical model and experimental registration. For comparison the measured electrical power directly on heat pump input plugs and calculated electrical power using model described by this paper.

For MATLAB based calculation model were used the evaporator inlet temperature measured in experiment together with logarithmic medium temperature given by Equation (6). Compressor efficiency were set at 0.5083 value obtained as a mean value of measured data. The comparison shows similar results for compressor electrical demand when a specific condenser power is took by experimental measurement and evaluated as a thermal balance of water in heat exchanger secondary circuit.
Comparing both curves, in electrical power measurements can be observed a thermal inertia which smooth the line. For calculated values, the model used a sampled data for air temperature at evaporator, and condenser water temperature at the condenser, both behavior of equipment having less inertial typo comparing the entire system.

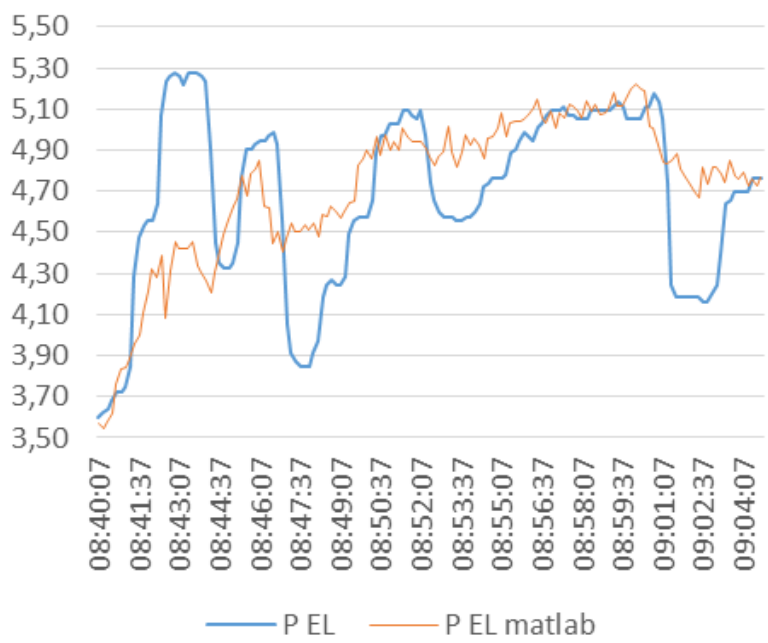

Fig. 15. Compressor electrical power from 21.02.2018 measurement and MATLAB based model

Future modelling research and parameters investigation can be done. Some simplifying techniques were used, like no thermal inertia considered in the system or averaging the measurements to extract a value of interest to be used after in the simulation. Also, in the heat pump, a more realistic evaluation can be done on pressure based measurements of refrigerant condensing and evaporating temperatures with electronic data acquisition station.

\section{References:}

1. C. Lamnatou, D. Chemisana, B. Lecoeuvre, C. Cristofari, and J.L. Canaletti, Concentrating photovoltaic/thermal system with thermal and electricity storage: CO2.eq emissions and multiple environmental indicators, J Clean Prod, 192, 376389 (2018)

https://doi.org/10.1016/j.jclepro.2018.04.205

2. Chr. Lamnatou, F. Motte, G.Noton, D. Chemisana and C. Cristofari, Building-integrated solar thermal system with/without phase change material: Life cycle assessment based on ReCiPe, USEtox and Ecological footprint, J. Environ. Manage., 212, 301-310 (2018)

https://doi.org/10.1016/j.jclepro.2018.05.032

3. F. Ascione, N. Bianco, R. F. De Masi, G. M. Mauro and G. P. Vanoli, Energy retrofit of educational buildings: Transient energy simulations, model calibration and multi-objective optimization 
towards nearly zero-energy performance, Energy Build, 144, 303-319 (2017)

https://doi.org/10.1016/j.enbuild.2017.03.056

4. A . Damm, J. Koberl, F. Prettenhaler, N. Rogler and C. Toglhofer, Impacts of $+2^{\circ} \mathrm{C}$ global warming on electricity demand in Europe, Clim Serv, 7, 12-30 (2017)

https://doi.org/10.1016/j.cliser.2016.07.001

5. C. Croitoru, I. Nastase, F. Bode, A. Meslem and A. Dogeanu, Thermal comfort models for indoor spaces and vehicles-Current capabilities and future perspectives, Renewable and Sustainable Energy Reviews, 44, 304-318 (2015)

https://doi.org/10.1016/j.rser.2014.10.105

6. M. Bernardoni, N. Delmonte, D. Chiozzi and P. Cova, Non-linear thermal simulation at system level: Compact modelling and experimental validation, Microelectronic Reliab, 80, 223-229 (2018)

https://doi.org/10.1016/j.microrel.2017.12.005

7. D. Cai, C. Qiu, J. Zhang, Y. Liu, X. Liang and G. $\mathrm{He}$, Performance analysis of a novel heat pump type air conditioner coupled with a liquid dehumidification/humidification cycle, Energy Convers Manag, 148, 1291-1305 (2017) https://doi.org/10.1016/j.enconman.2017.06.076

8. L. Sun, J. Wu, H. Jia and X. Liu, Research on fault detection method for heat pump air conditioning system under cold weather, Chin. J. Chem. Eng., 25, 1812-1819 (2017)

https://doi.org/10.1016/j.cjche.2017.06.009

9. Y. Zhang, Q. Ma, B. Li, X. Fan and Z. Fu, Application of an air source heat pump (ASHP) for heating in Harbin, the coldest provincial capital of China, Energy Build, 138, 96-103 (2017)

https://doi.org/10.1016/j.enbuild.2016.12.044 